\title{
Valued Insight or Act of Insubordination? How Context Shapes Coaches' Perceptions of Challenge-oriented Followership
}

Gottlieb, Marcus; Eys, Mark; Hardy, James; Benson, Alex J.

\section{Journal of Sport and Exercise Psychology}

DOI:

10.1123/jsep.2021-0122

Published: 01/12/2021

Peer reviewed version

Cyswllt i'r cyhoeddiad / Link to publication

Dyfyniad o'r fersiwn a gyhoeddwyd / Citation for published version (APA):

Gottlieb, M., Eys, M., Hardy, J., \& Benson, A. J. (2021). Valued Insight or Act of Insubordination? How Context Shapes Coaches' Perceptions of Challenge-oriented Followership. Journal of Sport and Exercise Psychology, 43(6), 488-496. https://doi.org/10.1123/jsep.2021-0122

\footnotetext{
Hawliau Cyffredinol / General rights

Copyright and moral rights for the publications made accessible in the public portal are retained by the authors and/or other copyright owners and it is a condition of accessing publications that users recognise and abide by the legal requirements associated with these rights.

- Users may download and print one copy of any publication from the public portal for the purpose of private study or research.

- You may not further distribute the material or use it for any profit-making activity or commercial gain

- You may freely distribute the URL identifying the publication in the public portal ?
}

Take down policy

If you believe that this document breaches copyright please contact us providing details, and we will remove access to the work immediately and investigate your claim. 

Challenge-oriented Followership ${ }^{1}$ Marcus Gottlieb, ${ }^{2}$ Mark Eys, 3James Hardy, \& ${ }^{1}$ Alex J. Benson

8 1University of Western Ontario, Department of Psychology

9 2Wilfrid Laurier University, Departments of Kinesiology and Physical Education and Psychology

10 3Bangor University, Institute for the Psychology of Elite Performance

Correspondence concerning this article should be addressed to Alex Benson, Social Science

13 Centre Rm 7418, Western University, London, Ontario, Canada, N6A 5C2, email:

14 abenson3@uwo.ca

17 Accepted for publication in Journal of Sport and Exercise Psychology (August 14, 2021).

18 This paper is not the copy of record and may not exactly replicate the authoritative document

19 published in the Journal of Sport and Exercise Psychology. The final article is available, upon

20 publication, at: https://doi.org/10.1123/jsep.2021-0122

22 Funding Acknowledgement: This research was completed with the support of a North American

23 Society for the Psychology of Sport \& Physical Activity graduate student research grant.

25 Date accepted: August 14, 2021

26 Main text word count: 6532

27 Reference word count: 1314

28 Tables: 2 
Abstract

31 Effective leadership is a collaborative effort, requiring a degree of complementarity in how

32 people enact roles of leadership and followership. Using a novel online vignette methodology,

33 we experimentally tested how three contextual factors influenced coaches' responses to

34 challenge-oriented acts of followership as well as investigated two potential mechanisms.

35 Coaches $(N=232)$ watched videos of an athlete provided unsolicited challenge-oriented

36 feedback to a coach. Videos varied by the (a) athlete's status, (b) presence of third-party

37 observers, and (c) stage of the decision-making process. Following the video, we assessed

38 coaches' evaluations of the athlete. Challenge-oriented followership was perceived more

39 favorably when enacted by an athlete in one-on-one (versus in a group) and before a decision

40 has been reached (versus after a decision is reached). Coaches may appreciate proactivity from

41 athletes in positions of followership, but challenge-oriented followership behaviors enacted at

42 the wrong time and place can elicit negative reactions.

43

44 Keywords: Follower; Leader; Leadership; Proactive, Role Perceptions

45

46

47 
Valued Insight or Act of Insubordination? How Context Shapes Coaches' Perceptions of

Society disproportionately recognizes leaders for their efforts in motivating individuals

51 toward a collective purpose (i.e., a romanticism of leadership; Meindl et al., 1985). Leadership,

52 however, cannot exist in the absence of followership (van Vugt et al., 2008). As described within

53 the leadership process framework, effective leadership is the result of a collaborative effort

54 between leaders and followers (Uhl-Bien et al., 2014). Rather than exclusively focusing on the

55 social influence of a single individual (and the behaviors that underpin such influence), this

56 framework emphasizes that leadership is a process of social influence that arises from how two

57 or more individuals engage in acts of leading and following (Uhl-Bien et al., 2014). As

58 individuals can flexibly navigate between roles of leading and following to accommodate the

59 situational demands a group is currently facing, complementary patterns of leading and

60 following are essential to group coordination and the pursuit of instrumental group objectives

61 (Eys et al., 2020). Although conventional wisdom implies that coaches and athletes need each

62 other to succeed-a point supported by abundant empirical evidence and theorizing specific to

63 coach-athlete relationships (e.g., Davis et al., 2019; Jowett, 2017) -research on how specific acts

64 of followership shape the leadership process in sport settings remains scarce.

65 Followership is defined as "the characteristics, behaviors, and processes of individuals

66 acting in relation to leaders" (Uhl-Bien et al., 2014, p. 96). This definition is value-neutral;

67 followership is not inherently positive or negative, nor does the term imply a static role of

68 subordination. Indeed, research in workplace settings has explored the various beliefs leaders

69 hold about followers, revealing that prototypical followership entails the facets of good

70 citizenship, enthusiasm, and industriousness, whereas antiprototypical followership entails the

71 facets of insubordination, incompetence, and conformity (Sy, 2010). Another important element

72 emphasized within Uhl-Bien et al.'s (2014) definition is the interdependent nature of leading

73 and following. Interdependence between leaders (e.g., coaches) and followers (e.g., athletes) is 
74 especially apparent in sport, making the athletic context a fertile ground to study leader-follower

75 interactions (Benson et al. 2014; Jowett \& Shanmugam, 2016). Notably, high quality coach-

76 athlete relationships are necessary for effective and purposeful coaching (Jowett, 2017) and

77 fruitful interactions between these two parties predict favorable outcomes (Nicholls et al., 2017).

78 To gain insight into the nature of followership in sport, Benson et al. (2016) interviewed

79 highly accomplished university sport coaches. These coaches described ideal followers as

80 individuals who are accountable and committed to supporting team efforts, while also being

81 proactive and willing to challenge ideas and offer alternative perspectives. A caveat echoed by

82 the coaches, however, was that followers had to understand when and where it was appropriate

83 to engage in such challenge-oriented behaviors. These findings advanced earlier work in the

84 organizational domain demonstrating that leaders preferred followers who were proactive in

85 their role and voiced their opinions (Sy, 2010), but that leaders' reactions to this proactive

86 followership was contingent on the situation in which they were enacted and the way such

87 behaviors were expressed (Sun \& van Emmerik, 2014; Whiting et al., 2012). In sport team

88 settings, acts of challenge-oriented followership can be a double-edged sword due to the mixed

89 reactions they can evoke from leaders, and how they may enhance or undermine planning and

90 coordination among team members (Benson et al., 2016). These findings suggest that similar to

91 leadership, followership is a process of social influence that requires situational awareness of

92 how context shapes the appropriateness of behaviors. As such, there is a need to better

93 understand how context affects coaches' perceptions of challenge-oriented followership

94 behaviors.

95 According to organizational literature, an important feature of challenge-oriented

96 followership is that it is a proactive and self-initiated behavior, meaning it is enacted without

97 prior instruction or permission from a leader (Grant \& Ashford, 2008; Grant et al., 2009).

98 Leaders may respond negatively to challenge-oriented followership if they perceive the behavior

99 as threatening or insubordinate (Falbe \& Yukl, 1992), a dishonest ingratiation attempt (Bolino, 
1999), or an overstepping of boundaries (Uhl-Bien et al., 2014). Nevertheless, challenge-

101 oriented followership may help to curtail selfish decisions made by some leaders (Oc \&

102 Bashshur, 2013), and aid in team decision-making processes (Benson et al., 2016). Thus, how

103 challenge-oriented followership is perceived by a leader may ultimately depend on the context in

104 which such behaviors occur (Carsten et al., 2018). In sport, there may be situations when a

105 coach (often the formal team-leader) requires immediate deference and compliance from the

106 athletes on their team (the followers) to move forward with a strategy or task (e.g., the time

107 pressure situation of a basketball timeout). In contrast, there are times when leaders desire

108 followers who are proactive in their role and willing to challenge their ideas and strategies (e.g.,

109 in a pre-season team goal setting session). In the current research, we conducted the first

110 experimental test of how three specific contextual factors (i.e., presence of third-parties, stage of

111 the decision-making process, and status of follower)-previously identified through interviews

112 with coaches (Benson et al., 2016)-influenced leaders' responses to challenge-oriented acts of

113 followership. Specifically, we examined how the context in which the acts occurred influenced

114 coaches' appraisals of the behaviour by assessing (a) perceived effectiveness of the athlete's

115 communication, (b) leader receptivity to the feedback, and (c) general evaluations of the

116 athlete's followership. As it pertains to the latter, on the basis of research on implicit

117 followership theory, we evaluated whether coaches perceived the athlete as having traits

118 associated with prototypical followership and insubordinate followership (Sy, 2010), which is

119 the only component of antiprototypical followership that predicts whether followers will refuse

120 their leaders' instructions (Knoll et al., 2017).

121 According to qualitative work exploring coaches' intepretations of followership in sport

122 (Benson et al., 2016), one contextual factor that may affect how challenge-oriented behaviors are

123 interpreted is the presence of third-party observers. DeRue and Ashford (2010) posited that

124 successful leadership efforts are based upon mutual understanding between leaders and

125 followers; when one person lays claim to leadership in a situation, others must grant this 
126 person's claims by actively assuming a follower identity. Whereas visible displays of deference

127 are critical to ensuring group members collectively endorse the same central leader, followers 128 who challenge their leaders in front of other group members may create ambiguity over who is 129 leading who. From the perspective of a formally appointed leader like a coach, such challenging 130 behaviors may be perceived as acts of insubordination. In contrast, followers who publicly 131 support their leader and/or wait for one-on-one interactions to challenge are less likely to 132 disrupt the central leadership structure within the group. As such, our first hypothesis was as 133 follows:

Hypothesis 1: Coaches will rate challenge-oriented acts of followership more positively in terms of (a) perceived effectiveness, (b) receptivity, and (c) general evaluations of the follower (i.e., higher levels of prototypical followership, lower levels of insubordinate followership)-when they occur in a one-on-one setting than in a group setting. Coaches also identified that the timing of challenge-oriented acts of followership may affect their perceptions (Benson et al., 2016). Leaders tend to view feedback negatively when it is given too close to when a decision must be made (Whiting et al., 2012). Once the deliberation 141 phase for a given decision has passed, any further input may obstruct rather than assist 142 decision-making processes (Marks et al., 2001). Following this rationale, we hypothesized the 143 following:

Hypothesis 2: Coaches will rate challenge-oriented acts of followership more positively in terms of (a) perceived effectiveness, (b) receptivity, and (c) general evaluations of the follower (i.e., higher levels of prototypical followership, lower levels of insubordinate followership)—when they occur before closure on a decision is signaled (i.e., before a decision is made) than after a decision is signaled (i.e., after a decision is made).

150 their understanding of challenge-oriented behaviors (Benson et al., 2016). Oc and Bashshur 151 (2013) proposed that followers are more likely to influence their leaders when they occupy a 
152 higher status position within the group. Individuals with higher status (i.e., respect and 153 admiration) tend to receive more opportunities and have greater access to resources within 154 groups (Anderson et al., 2015). As status is conferred to individuals based on their perceived 155 instrumental value to a group (Anderson et al., 2015), coaches may be more receptive to 156 feedback from higher status group members. Nevertheless, challenge-oriented followership 157 behaviors from high-status followers enacted at the wrong time (i.e., in the presence of third158 party observers; Benson et al., 2016) may pose a threat to leaders by undermining their 159 authority and disrupting the leadership hierarchy (van Vugt et al., 2008). As such, we 160 hypothesized the following:

Hypothesis 3: Coaches will rate challenge-oriented acts of followership more positively in terms of (a) perceived effectiveness, (b) receptivity, and (c) general evaluations of the follower (i.e., higher levels of prototypical followership, lower levels of insubordinate followership) - when they are enacted from a higher status than lower status teammate, as long as no other contextual boundaries are violated (i.e., one-on-one setting, before a decision is reached).

170 positively (i.e., indirect effects). Understanding why coaches arrived at certain evaluations 171 would help to guide efforts to improve leader-follower communication patterns in sport. We 172 tested two candidate mechanisms in the current study. Given the lack of direct evidence in this 173 domain, we briefly highlight rationale for considering these particular mediators.

174 One potential mediator is the extent to which challenge-oriented followership is 175 perceived as an expression of dominance. Evolutionary research on leader-follower dynamics 176 suggests that dominant individuals may gain influence through forced compliance (instead of 177 persuasion) by relying on fear and intimidation tactics (Bastardoz \& van Vugt, 2019; Cheng et 
178 al., 2010). In research on nonhuman primates, expressions of dominance by subordinates

179 directly threaten the alpha individual and often elicit aggressive countermeasures (Sapolsky,

180 2005). As such, perceptions of follower dominance may mediate the effect of challenge-oriented

181 followership on how coaches evaluate and respond to such behavior in the presence of third-

182 party observers or after a decision is made. Another candidate mechanism is the extent to which

183 challenge-oriented followership is perceived as a violation of role expectations. Coaches develop

184 and communicate specific and general role expectations to ensure athletes are positively

185 contributing to the direction of the team (Eys et al., 2020). Challenge-oriented followership may

186 contravene such expectations when enacted at the wrong moment, such as in the presence of

187 others or after a decision is made. Altogether, we explored the following research questions:

188 Research Questions: Is the effect of challenge-oriented followership, (a) in the

189 presence of third-party observers and (b) after a decision is made, on coaches'

190 evaluations mediated by either (1) follower dominance or (2) violation of role

$191 \quad$ expectations?

192 Overview of the Current Research

193 The objective of the proposed research was to experimentally test how specific contextual

194 factors influence leaders' (i.e., coaches') responses to challenge-oriented acts of followership. To

195 examine this question, we introduce a novel experimental vignette methodology in which we

196 filmed leader-follower interactions using paid actors. Such an approach enabled us to directly

197 manipulate three contexts (i.e., presence of third-party observers, stage of the decision-making

198 process, follower status) in which a follower delivered challenge-oriented feedback. Using this

199 methodology enhances the study design's internal validity and strengthens our confidence in

200 making causal inferences (Scandura \& Williams, 2000). Moreover, instead of asking

201 participants to envision themselves in a scenario based on a written description, having

202 participants observe a video that depicts an actual leader-follower interaction creates a more 
203 immersive and realistic vignette experience, and controls for other factors such as content of the

204 feedback (Pierce \& Aguinis, 1998).

\section{Method}

\section{Participants}

The final sample consisted of 232 coaches $\left(n_{\text {females }}=67 ; M_{\text {age }}=37.90, S D=13.02\right)$

208 who coached at either the collegiate $(n=139)$, youth $(n=40)$, club $(n=32)$, or recreational

$209(n=21)$ level. Table 1 depicts how coaches' competition level varied by gender. We obtained

210338 initial responses; however, many coaches $(n=91)$ were not able to complete the

211 experiment due to technical difficulties (i.e., the video did not load properly due to software

212 compatibility issues or the audio was inadequate). An additional 15 coaches were excluded

213 for failing one of the manipulation checks (detailed below). The average number of years of

214 coaching experience in our sample was $13.34(S D=10.36)$. More coaches self-identified as

215 head $(n=163)$ than assistant $(n=67)$ coaches (two coaches did not respond to this

216 question). There were slightly more coaches of male-only teams $(n=96)$ than female-only

217 teams $(n=94)$; some coaches $(n=42)$ coached both male and female teams. The individuals

218 in our sample coached a variety of different sports, including basketball $(n=50)$, volleyball

$219(n=41)$, hockey $(n=30)$, soccer $(n=27)$, football $(n=15)$, rugby $(n=10)$, baseball $(n=8)$,

220 and other sports (e.g., track and field, swimming, curling, dance, field hockey, golf; $n=51$ ).

\section{$221 \quad$ Procedure and Materials}

222 After obtaining approval from two institutional ethics boards (i.e., Western

223 University and Wilfred Laurier University), coaches were recruited via the internet. As there

224 were no comparable experimental designs from which to inform our assumed effect size for

225 the power analysis, we targeted the smallest effect size of interest given the funding available

226 for recruitment (i.e., small-to-medium sized effect). An a priori power analysis (estimated

227 effect of $f=0.175, \alpha=.05$ ) indicated that 259 coaches would be required to achieve a power

228 of .80. Thus, we sought to obtain 32 coaches per condition (i.e., 256 coaches total). Our 
229 primary recruitment method was searching publicly available coaching databases to obtain

230 head and assistant coaches' email addresses-beginning with the collegiate level of

231 competition. We used this method to email over 500 coaches in Canada and the United

232 States to gauge interest in participation. As a secondary recruitment strategy after not

233 obtaining enough complete responses from university coaches, we broadened our sampling

234 criteria and information posts were distributed on social media. Coaching experience was

235 verified once initial contact was made in all cases; coaches were emailed a unique study link

236 to ensure experimenter control over who was included.

237 Experimental Vignettes

238 Coaches who consented to participate first completed a demographic questionnaire.

239 They were then randomly assigned to view one of eight video vignettes (created for the

240 purposes of this study). The vignettes depicted an athlete speaking up and verbally

241 challenging a coach during a meeting-hereafter referred to as challenge-oriented

242 followership (COF). The individuals in the vignettes were paid male actors and the actor

243 portraying the coach was a professional coach at the collegiate level-none of whom were

244 part of the research team. Using a full-factorial $2 \times 2 \times 2$ experimental design, three

245 contextual factors were manipulated. We manipulated the status of the follower (i.e., high

246 status vs. low status) via the following instructions given to participants immediately prior to

247 watching the video:

248 Once you click on the next page you will be taken to a short video (i.e., just over a 249 minute long) depicting an interaction between a coach and several athletes. In the 250 following video clip, please pay careful attention to the athlete wearing the black 251 shirt, who is a [respected senior team member/newcomer to the team this year].

252 Immediately following the video clip, we will be asking for your thoughts on how you, 253 as a coach, feel about the specific interaction with the [senior athlete/newcomer] in 
the black shirt. We would like you to imagine yourself as the coach interacting with a team member in the following clip....

We manipulated the presence of third-party observers by depicting the athlete

257 enacting the COF as either accompanied by four teammates (group condition) or alone (one-

258 on-one condition). Finally, we also manipulated the stage of the decision-making process:

259 The COF occurred either before the coach had announced his decision as final (before

260 condition) or after his announcement (after condition). The content of the follower's

261 feedback and the nature of the discussion led by the coach remained constant across the

262 scenarios. After viewing the vignette, participants completed questionnaires of their

263 perceptions of the follower and his feedback. See the supplementary material file for

264 additional information about the vignettes: https://osf.io/cwfhe/

\section{Dependent Measures}

266 Effectiveness of Follower Behavior. We adapted Sauer's (2011) measure of

267 leader effectiveness to develop three items that evaluated the degree to which coaches

268 perceived the COF to be effective in the context of advancing team goals. These items related

269 to the perceived effectiveness of the COF ("To what extent was the athlete effective in his role

270 as a follower?”; “To what extent was the athlete's behavior characteristic of ideal

271 followership"; "To what extent did the athlete positively contribute to the team meeting in

272 this situation?”), with response options ranging from 1 (not at all) to 7 (very much so).

273 Leader Receptivity to Feedback. Coaches were asked to indicate the extent to

274 which they were receptive to the athlete's COF on three items, with response options ranging

275 from 1 (not at all) to 7 (very much so). The items were: "I would carefully consider the

276 athlete's feedback under these circumstances."; "I would pay close attention to the athlete's

277 suggestion in this situation."; "I would be receptive to the athlete's advice in this situation."

278 Evaluations of the Follower. We modified Sy’s (2010) Implicit Followership

279 Scale to assess coaches' evaluation of the athlete depicted in the vignette. Specifically, 
280 coaches were asked to rate "how characteristic each adjective is of the player [they] just

281 observed in the previous interaction” with response options ranging from 1 (not at all

282 characteristic) to 10 (extremely characteristic). This scale captures both prototypical and

283 antiprototypical follower traits, but was initially designed as a trait measure in a workplace

284 context. In modifying the questionnaire for this experimental context, ten items (i.e.,

285 adjectives) were excluded from the original scale (i.e., hardworking, uneducated, easily

286 influenced, slow, excited, follows trends, outgoing, inexperienced, soft spoken, happy),

287 leaving five items reflecting prototypical followership (i.e., loyal, productive, reliable, goes

288 above and beyond, team player) and three items reflecting insubordinate followership-a

289 specific facet of antiprototypical followership (i.e., arrogant, rude, bad temper). ${ }^{1}$

290 Dominance. Four items were adapted from Cheng et al.'s (2010) Dominance and

291 Prestige scale to assess the extent to which coaches perceived the target athlete as dominant.

292 Coaches were asked to rate the extent to which they agreed with the four statements, with

293 response options ranging from 1 (strongly disagree) to 7 (strongly agree). The items

294 included were, "This athlete is concerned with demonstrating control over others"; "This

295 athlete is willing to use aggressive verbal tactics to get his way"; "This athlete has a forceful

296 personality"; “This athlete enjoys having authority over others.”

297 Role Violation. To assess whether coaches perceived the athlete to be in violation

298 of his role, we created three items specifically for this study. Coaches were asked to rate the

299 extent to which they agreed with three items related to role violation, with response options

300 ranging from 1 (strongly disagree) to 7 (strongly agree). These items were, "This athlete

301 clearly violated his role under these circumstances”; “The athlete's behavior was

302 inappropriate in this situation"; "I would not encourage this type of behavior in my group."

\footnotetext{
${ }^{1}$ A confirmatory factor analysis evaluating this two-factor structure demonstrated the following model fit, $\chi 2(19)=$ $41.13, p<.001, \mathrm{CFI}=0.96, \mathrm{TLI}=0.94, \mathrm{RMSEA}=0.08,95 \% \mathrm{CI}[0.05,0.11]$, SRMR $=0.47$, with factor loadings ranging from .68 to .85 .
} 


\section{Manipulation and Deception Checks}

Finally, coaches completed three multiple-choice manipulation check questions to ensure coaches could recall the context surrounding the interaction (i.e., "How many athletes were present during the interaction you observed?"; "Which of the following best reflects the athlete you observed during the video?"; "Which of the following reflects the athlete's behavior?”). To gauge coaches' naiveté regarding the study, coaches also responded to an open-ended question about whether they developed their own ideas about the study's purpose and hypotheses. Of the 247 coaches who completed the full experiment, 15 coaches were excluded for incorrectly responding to one of the manipulation check questions.

\section{Analysis}

We used confirmatory factor analysis to model scores derived from each subscale as a latent factor in Mplus 8.4 (Muthén \& Muthén, 2017). The overall measurement model yielded the following fit indices, $\chi^{2}(174)=364.71, p<.001$, RMSEA $=0.07$, CFI $=0.93$, TLI $=0.92, \mathrm{SRMR}=.09$. Although the RMSEA and SRMR values exceed the recommended cutoff values by Hu and Bentler (1999), these indices should be interpreted in the context of measurement quality, as the standardized factor loadings are strong and significant ranging from .54 to .96, with an average factor loading of .80 (McNeish \& Hancock, 2018).

Nonetheless, inspecting the modification indices revealed that fit markedly improves when allowing the residual error term to correlate for items one and two of the follower effectiveness subscale, $\chi^{2}(173)=267.108, p<.001$, RMSEA $=0.05$, CFI $=0.97$, TLI $=0.96$, SRMR $=.04$. This suggested modification may reflect the fact that these items used the term "follower/followership", whereas the third item did not. Most of the interfactor correlations were moderate, but the correlation between insubordinate and dominance was strong at $r=$ .80. All of the subscale scores demonstrated sufficient levels of reliability (effectiveness of follower behavior, $\alpha=.76$, leader receptivity to feedback, $\alpha=.87$; prototypical followership, $\alpha=.88$; insubordinate followership, $\alpha=.83$; dominance, $\alpha=.88$; role violation, $\alpha=.92$ ). 
To evaluate the substantive hypotheses, full-factorial analyses of variance (ANOVA) were conducted to test the main and interactive effects of the contextual variables on how

331 coaches evaluated the COF. Significant interaction effects were followed by pairwise

332 comparisons to evaluate differences among specific combinations of factors using the least 333 significant differences method.

\section{Results}

As Little's MCAR was non-significant, $X^{2}(460)=471.17, p=.349$, the expectationmaximization algorithm was used to replace missing data from incomplete responses (Schafer \&

337 Olsen, 1998). Levene’s test of homogeneity of variance was also non-significant across all

338 variables ( $p \mathrm{~s} \geq 0.322$ ), fulfilling the assumption that variance between conditions was

339 approximately equal. Fisher's exact tests were used to compare responses for coaching level,

340 gender of the coach, and gender of the team coached across the three experimental conditions.

341 This analysis revealed no significant relations between these demographic variables and the 342 experimental conditions ( $p$ s $\geq$.149). A one-way ANOVA also revealed that participant age did 343 not significantly differ between conditions, $F \mathrm{~s} \leq 1.10, p s \geq .331$.

\section{Coaches' Evaluations of Followership}

345 Descriptive statistics are displayed in Table 2. As seen in the table, scores fell near the 346 midpoint of the scale for the majority of measures, suggesting that, on average, coaches deemed

347 the act of challenge-oriented feedback to be relatively neutral. In the following analyses, we 348 examined the degree to which contextual factors shifted coaches' evaluations of such behaviors.

\section{Effectiveness of Follower Behavior}

350 Although there were no significant main effects related to the status of follower,

$351 F(1,223)=.92, p=.338, \eta_{\mathrm{p}}^{2}=.00$, or the stage of the decision-making process, $F(1,223)$

$352=2.41, p=.115, \eta_{\mathrm{p}}{ }^{2}=.01$, perceived effectiveness of the feedback differed based on the

353 presence of third-party observers, $F(1,223)=4.07, p=.045, \eta_{p}^{2}=.02$. Supporting

354 Hypothesis 1, coaches perceived the COF as more effective when it was delivered 
355 individually $(M=3.68, S D=1.32)$ than in a group context $(M=3.33, S D=1.36)$. Of

356 note, there was a significant interaction between presence of third-party observers and

357 stage of the decision-making process, $F(1,223)=5.40, p=.021, \eta_{\mathrm{p}^{2}}=.02$. The COF

358 delivered after a decision was reached was perceived as more effective when it occurred

359 individually $(M=3.75 ; S D=1.37)$ than in a group $(M=3.00 ; S D=1.24), p=.003$,

360 Hedges's $g=1.08$. There was also a significant interaction between presence of third-

361 party observers and status of follower, $F(1,223)=4.23, p=.041, \eta_{\mathrm{p}}{ }^{2}=.02$. COF enacted

362 by a newcomer (i.e., lower status member) was perceived as more effective when enacted

363 individually $(M=3.78 ; S D=1.29)$ than in a group $(M=3.01 ; S D=1.26), p=.005$,

364 Hedges's $g=0.60$. The two-way interaction between status of follower and stage of the

365 decision-making process, $F(1,223)=.000, p=.990, \eta_{\mathrm{p}}{ }^{2}=.00$, and three-way

366 interaction, $F(1,223)=0.11, p=.740, \eta_{\mathrm{p}^{2}}=.00$, were nonsignificant.

\section{$367 \quad$ Leader Receptivity}

368 There were no significant main effects of any contextual variables on leader's

369 receptivity to the COF: status of follower, $F(1,224)=1.709, p=.192, \eta_{\mathrm{p}}{ }^{2}=.01$, presence

370 of third-party observers, $F(1,224)=2.542, p=.112, \eta_{\mathrm{p}}{ }^{2}=.01$, stage of the decision-

371 making process, $F(1,224)=0.104, p=.747, \eta_{\mathrm{p}}{ }^{2}=.00$. Nonetheless, a significant

372 interaction effect was found between stage of the decision-making process and presence

373 of third-party observers, $F(1,224)=4.281, p=.040, \eta_{\mathrm{p}^{2}}{ }^{2}=.02$. When COF was delivered

374 after a decision was reached, coaches were more receptive to the COF when it was

375 enacted individually $(M=5.28 ; S D=1.08)$ than in a group setting $(M=4.70 ; S D=1.37)$,

$376 p=.012$, Hedges's $g=0.46$. Despite this finding, there were no other interaction effects

377 detected, including between presence of third-party observers and status of follower, $F(1$,

$378224)=0.223, p=.637, \eta_{\mathrm{p}}^{2}=.00$, or status of follower and stage of the decision-making

379 process, $F(1,224)=3.283, p=.071, \eta_{\mathrm{p}^{2}}=.01$. The three-way interaction was also non-

380 significant, $F(1,224)=0.30, p=.864, \eta_{\mathrm{p}}{ }^{2}=.00$. 
Prototypical Followership

Ratings of prototypical followership varied according to the stage of the decisionmaking process, $F(1,220)=4.37, p=.038, \eta_{\mathrm{p}}{ }^{2}=.02$. Supporting Hypothesis 2 , coaches rated the athlete higher on prototypical followership characteristics when the COF was enacted before a decision was made $(M=5.88 ; S D=1.15)$ than after $(M=5.62, S D=$ 1.30) a decision was made. Conversely, there were no main effects of follower status, $F(1$, $220)=1.51, p=.221, \eta_{\mathrm{p}}{ }^{2}=.007$, or presence of third-party observers, $F(1,224)=0.05, p$

$388=.921, \eta_{\mathrm{p}}^{2}=.000$, on prototypical followership. There were also no significant

389 interaction effects between the presence of third-party observers and status of follower, $F(1,220)=0.32, p=.570, \eta_{\mathrm{p}}{ }^{2}=.001$, status of follower and stage of the decision-making process, $F(1,220)=0.14, p=.707, \eta_{\mathrm{p}}{ }^{2}=.00$, or stage of the decision-making process and

392 presence of third-party observers, $F(1,220)=2.45, p=.119, \eta_{\mathrm{p}}{ }^{2}=.01$. The three-way

393 interaction was also nonsignificant, $F(1,220)=1.75, p=.187, \eta_{\mathrm{p}}{ }^{2}=.01$.

\section{Insubordinate Followership}

Counter to predictions, there were no significant main or interactive effects related to insubordinate followership (see supplementary file for complete statistics). Potential Mediators

Similarly, analyses revealed that neither of the potential mediators (i.e., perceptions of follower dominance, perceived role violation) exhibited differences across conditions (i.e., first linkage in the mediation pathway) that merited proceeding to

401 evaluating them as potential mediators linking COF to coaches' evaluations of such 402 behavior (see supplementary file for complete statistics).

\section{Discussion}

Followership is a process of social influence that is tightly intertwined with the 405 process of leadership (Uhl-Bien et al., 2014). In sports, positive relationships between 406 leaders (e.g., coaches) and followers (e.g., athletes) are a key component of successful 
407 team performance (Davis et al., 2019), yet there is a scarcity of systematic research on

408 the nature of followership and its consequences in sport. The present study is the first to

409 use an experimental vignette methodology to examine whether contextual factors

410 previously identified by coaches (i.e., presence of third-parties, stage of the decision-

411 making process, and status of follower; Benson et al., 2016) impacted coaches'

412 evaluations of both $\mathrm{COF}$ and the athlete enacting the challenging behavior. Analyses

413 revealed the presence of higher-order interaction effects of context on leaders'

414 interpretations of follower behavior. As commonly observed in research examining

415 interpersonal exchanges, the setting, complexity, breadth, and nuance of social

416 interactions means that several contextual factors ought to be accounted for in a given

417 analysis (Kenny, 1996).

418 Nonetheless, of the factors manipulated, the presence of third-party observers

419 (i.e., teammates) appeared to be the most salient factor influencing coaches' evaluations.

420 Coaches perceived COF to be more effective in a one-on-one setting than in the presence

421 of others. The timing of the COF was also relevant to coaches' evaluations; a preference

422 for COF enacted before (rather than after) a decision emerged. Generally, coaches'

423 evaluations of the COF were relatively neutral (mean responses clustered around the

424 midpoint of the measures), suggesting that the behavior itself was not deemed inherently

425 positive or negative. As the context the COF occurred within appeared to skew coaches'

426 appraisals away from the midpoint of the scales (i.e., positively or negatively), this

427 underscores the notion that COF is indeed a double-edged sword (e.g., Benson et al.,

428 2016; Carsten et al., 2018).

429 Theoretical Implications

430 A major contribution of this study was that the presence of third-party observers affected

431 how coaches evaluated COF. Providing support for our first hypothesis, coaches rated the COF

432 as more effective when enacted by the athlete one-on-one than in the presence of teammates. 
433 Moreover, the presence of interaction effects indicated that delivering COF in a one-on-one

434 setting (instead of in front on teammates) may have actually buffered against the costs of

435 violating other norms-namely, speaking up after a decision was made or as a low status group

436 member. In such situations, coaches responded more favourably to the COF in terms of

437 perceived effectiveness and receptivity when enacted individually. Altogether, the pattern of

438 findings suggests that when other contextual conditions are violated (i.e., speaking up after a

439 final decision is made, speaking up as a new group member), the mere presence of others may

440 play a role in how such behaviors are interpreted by coaches. This aligns with research spanning

441 several populations (e.g., elementary school students, Archer-Kath et al., 1994; medical

442 students, Camp et al., 2010) whereby feedback is received more positively when delivered one-

443 on-one compared to in a group. Indeed, publicly disagreeing with a leader or offering an

444 alternative solution could be construed as threatening to the leader (Camp et al., 2010; Oc \&

445 Bashshur, 2013). In the context of sport, the coach-athlete relationship is highly interdependent

446 and thrives due to the presence of complementarity, commitment, closeness, and co-orientation

447 (see Jowett, 2017). When an athlete challenges in front of teammates, it may signal a mismatch

448 (or absence) in these values, leading to the coach perceiving such behavior as threatening to

449 their standing.

450 Our study also adds to the literature by showing how challenge-oriented behaviors can

451 be a component of prototypical followership. In partial support of the second hypothesis,

452 athletes engaging in COF before a decision was made (rather than after) tend to be perceived as

453 a prototypical follower (i.e., loyal, productive, reliable, goes above and beyond, and is a team

454 player). Research on workplace interactions have emphasized that timing is important to

455 determining how leaders evaluate follower feedback (e.g., Whiting et al., 2012), as it can signal

456 proactivity (Grant \& Ashford, 2008). Leaders, however, do not always appreciate proactive

457 behavior (Grant et al., 2009; Grant \& Ashford, 2008), despite the fact that it can contribute to

458 various positive work outcomes (see Parker et al., 2010). In sport, teams benefit from players 
459 who proactively correct each other and voice suggestions to overcome obstacles (Van

460 Puyenbroeck et al., 2018). Prior to the present study, however, coaches' evaluations of this

461 proactive behavior had not been experimentally examined. Our findings suggest that coaches

462 prefer when athletes enact early proactive behaviors (i.e., enact COF before a decision is made).

463 Although the third hypothesis was not supported (i.e., follower status did not affect

464 coaches' evaluations), this may reflect the nature of the vignette design rather than the

465 importance of a follower's status. As status refers to the respect, admiration, and voluntary

466 deference afforded to an individual based on their instrumental social value (Anderson et al.,

467 2015), the status manipulation may have lacked experimental realism in contrast to the other

468 contextual factors that were varied across conditions (i.e., timing of feedback, presence of third-

469 party observers). According to social impact theory (Latané, 1981), followers of higher social

470 rank have a greater capacity to influence leaders because of their relative proximity to the leader

471 (Oc \& Bashshur, 2013). Moving forward, research should consider differences between what

472 leaders prefer from their followers and what is beneficial for team outcomes (Fuller et al., 2012).

473 Whereas qualitative work described how coaches preferred feedback from higher-status

474 followers (Benson et al., 2016), research in organizational settings suggests that dissent from

475 lower-status followers is associated with improvements in group decision making processes (De

476 Dreu \& West, 2001). Indeed, lower status followers may be the primary drivers of innovation

477 and change as they stimulate a broader range of ideas (Blair \& Bligh, 2018). Despite the absence

478 of status-based effects in the current study, organizational scholars have drawn attention to the

479 consequential role of status in shaping individual, interpersonal, and group consequences

480 (Bendersky \& Pai, 2018), and thus it is perhaps premature to rule out this important variable in 481 relation to leader-follower dynamics in sport teams.

\section{Practical Implications}

483 Speaking up and providing alternative points of view is an important aspect of being an

484 effective follower (Carsten et al., 2010; Sy, 2010), but it can also lead to ruptures in leader- 
485 follower relationships (Grant \& Ashford, 2008; Uhl-Bien et al., 2014). Thus, it is perhaps

486 unsurprising that followers often fear retaliation when providing feedback to superiors (Kudisch

487 et al., 2006). In sport teams, open and honest communication between coaches and athletes is

488 vital to predicting team outcomes (see Davis et al., 2019). Coaches understand the importance of

489 feedback given from the athletes on their team, but recognize they are not always open to

490 receiving it (Mason et al., 2020). As such, athletes may benefit from understanding how to more

491 effectively voice their ideas when they differ from their coach. Our results suggest that athletes

492 should approach their coach one-on-one to maximize the likelihood of conflicting ideas being

493 regarded as effective. They should also do so before their coach reaches a decision to increase

494 the chance they are perceived as a good follower. Establishing team norms consistent with these

495 recommendations may facilitate optimal team functioning.

\section{Limitations and Future directions}

497 Like all research, the present study should be considered recognizing its limitations.

498 Experimental video vignettes have inherent trade-offs as a methodology. Vignettes afford

499 researchers a high degree of control by enabling manipulations of specific variables while

500 effectively controlling for extraneous factors, which make them a useful way to establish cause-

501 and-effect relationships (Aguinis \& Bradley, 2014; Pierce \& Aguinis, 1998). However, creating

502 and implementing immersive experimental vignettes (i.e., filmed interactions) is resource

503 intensive and both the external validity and realism can be diminished (Scandura \& Williams,

504 2000). A few participants in the open-ended deception check, for example, noted that the

505 brevity of the coach-athlete interaction in the vignette did not provide enough information for

506 them to make an accurate assessment of the situation. Although minimal acquaintance

507 impressions are commonplace and consequential (Rule \& Ambady, 2008), this may explain the

508 gap between the present findings and prior qualitative research that emphasized the nuanced

509 interplay among all three contextual factors manipulated in the experimental vignettes (Benson

510 et al., 2016). Future research could study proactive followership behaviors with actual coach- 
511 athlete dyads to mitigate this limitation. Although such an approach would sacrifice

512 experimental control, studying the consequences of different types of followership behavior

513 (e.g., Uhl-Bien et al., 2014) in actual sport teams would help bridge the gap between laboratory

514 and in vivo settings.

515 Another limitation pertains to statistical power. Our final sample consisted of 232

516 coaches, which fell slightly below our target sample. Moreover, due to the automatic

517 randomization technique used (the gold-standard when using experimental methodologies to

518 assess human behavior; Dugard, 2014) and failed attention checks in specific conditions, an

519 uneven distribution of participants emerged across conditions. Thus, the study is at risk of

520 committing a Type II error and results ought to be interpreted with some caution. Future

521 researchers should focus on strategic and creative ways to tackle participant recruitment to

522 mitigate this limitation. An empirically supported (e.g., McCullagh et al., 2014) way to

523 accomplish this is partnering with organizations who can distribute the study internally. As the

524 present study was not preregistered, it would be informative to replicate these findings with a

525 high-powered sample. An additional benefit of using larger samples would be to implement

526 structural equation modelling to account for measurement error and model multiple dependent

527 measures in a single model (Breitsohl, 2019).

528 Having increased statistical power would also facilitate further sub-group comparisons.

529 It would be worthwhile, for instance, to determine whether the competition level of the coach or

530 the sport they coached affected how coaches evaluated the COF. Although there is scarce

531 research in this regard, qualitative evidence suggests that high-performance coaches (e.g.,

532 professional) across various sports welcome feedback from athletes on their team (Mason et al.,

533 2020). However, these findings have yet to be demonstrated quantitively; additional research is

534 needed to substantiate this relationship.

535 Coaches' individual differences were not accounted for and were not a focus of this study.

536 However, understanding how individual factors (e.g., personality composition) affected leaders' 
537 evaluations of COF would advance the literature in a meaningful way by generating individually 538 tailored advice for followers. In the military, for example, leaders who are higher in openness to 539 experience are more likely to be receptive to feedback (Smither et al., 2005). This type of 540 research has yet to be conducted in sport settings, yet it could elucidate differences in coaches' 541 individual receptivity to COF.

542 The present investigation focused on coach-athlete interactions as a proxy for the leader543 follower relationship due to the inherent power imbalance that exists between these roles. In 544 sports teams, however, certain individuals switch between leading and following. A team 545 captain, for example, must lead junior players while being subservient to the coach (who in turn 546 defers to the General Manager). Indeed, coaches report that navigating dual leader-follower 547 roles is an issue for many team members (Benson et al., 2016).

\section{Conclusion}

To advance the current understanding of followership in sport teams, this was the first study to 551 experimentally evaluate how coaches responded to an important but potentially contentious 552 social behavior. That is, we tested how coaches' perceptions of being challenged on their strategy 553 and tactics varied based on the context surrounding the interaction. We found no support for 554 our mediation-oriented expectations; however, coaches perceived such challenge-oriented 555 behavior more favourably when enacted by an athlete (a) one-on-one (versus in a group), and 556 (b) before a decision has been reached (versus after a decision is reached). In addition to making 557 a unique contribution to the sport literature on coach-athlete interactions, our findings add to 558 the body of organizational literature that seeks to impact macro improvements in leader559 follower interactions. These results can be used by practitioners to guide athletes who want to 560 strategically provide oppositional feedback to their coach, which is important to team success. 
References

563

564

565

566

567

568

569

570

571

572

573

574

575

576

577

578

579

580

581

582

583

584

585

586

Aguinis, H., \& Bradley, K. J. (2014). Best practice recommendations for designing and implementing experimental vignette methodology studies. Organizational Research Methods, 17(4), 351-371. https://doi.org/10.1177/1094428114547952

Anderson, C., Hildreth, J. A. D., \& Howland, L. (2015). Is the desire for status a fundamental human motive? A review of the empirical literature. Psychological Bulletin, 141(3), 574. https://doi.org/10.1037/aoo38781

Archer-Kath, J., Johnson, D. W., \& Johnson, R. T. (1994). Individual versus group feedback in cooperative groups. The Journal of Social Psychology, 134(5), 681-694. https://doi.org/10.1080/o0224545.1994.9922999

Bastardoz, N., \& van Vugt, M. (2019). The nature of followership: Evolutionary analysis and review. The Leadership Quarterly, 30(1), 81-95. https://doi.org/10.1016/j.leaqua.2018.09.004

Bendersky, C., \& Pai, J. (2018). Status dynamics. Annual Review of Organizational Psychology and Organizational Behavior, 5, 183-199. https://doi.org/10.1146/annurev-orgpsych032117-104602

Benson, A. J., Hardy, J., \& Eys, M. (2016). Contextualizing leaders' interpretations of proactive followership. Journal of Organizational Behavior, 37(7), 949-966. https://doi.org/10.1002/job.2077

Benson, A. J., Surya, M., \& Eys, M. A. (2014). The nature and transmission of roles in sport teams. Sport, Exercise, and Performance Psychology, 3(4), 228-240. https://doi.org/10.1037/spyooooo16

Blair, B. A., \& Bligh, M. C. (2018). Looking for leadership in all the wrong places: The impact of culture on proactive followership and follower dissent. Journal of Social Issues, 74(1), 129-143. https://doi.org/10.1111/josi.12260 
Bolino, M. C. (1999). Citizenship and impression management: Good soldiers or good actors? Academy of Management Review, 24(1), 82-98. https://doi.org/10.2307/259038

Breitsohl, H. (2019). Beyond ANOVA: An introduction to structural equation models for experimental designs. Organizational Research Methods, 22(3), 649-677. https://doi.org/10.1177/1094428118754988

Camp, C. L., Gregory, J. K., Lachman, N., Chen, L. P., Juskewitch, J. E., \& Pawlina, W. (2010). Comparative efficacy of group and individual feedback in gross anatomy for promoting medical student professionalism. Anatomical Sciences Education, 3(2), 64-72. https://doi.org/10.1002/ase.142

Carsten, M. K., Uhl-Bien, M., \& Huang, L. (2018). Leader perceptions and motivation as outcomes of followership role orientation and behavior. Leadership, 14(6), 731-756. https://doi.org/10.1177/1742715017720306

Cheng, J. T., Tracy, J. L., \& Henrich, J. (2010). Pride, personality, and the evolutionary foundations of human social status. Evolution and Human Behavior, 31, 334 -347. https://doi:10.1016/j.evolhumbehav.2010.02.004

Davis, L., Jowett, S., \& Tafvelin, S. (2019). Communication strategies: The fuel for quality coachathlete relationships and athlete satisfaction. Frontiers in Psychology, 10. https://doi.org/10.3389/fpsyg.2019.02156

De Dreu, C. K., \& West, M. A. (2001). Minority dissent and team innovation: The importance of participation in decision making. Journal of Applied Psychology, 86(6), 1191. https://doi:10.1037/0021-9010.86.6.1191

DeRue, D., \& Ashford, S. (2010). Who will lead and who will follow? A social process of leadership identity construction in organizations. The Academy of Management Review, 35(4), 627-647. https://doi.org/10.3389/fpsyg.2019.02156

Dugard, P. (2014). Randomization tests: A new gold standard? Journal of Contextual Behavioral Science, 3(1), 65-68. https://doi.org/10.1016/j.jcbs.2013.10.001 
613 Eys, M., Evans, M., \& Benson, A. (2020). Group dynamics in sport ( $5^{\text {th }}$ ed.). Fitness Information 614 Technology.

615 Falbe, C. M., \& Yukl, G. (1992). Consequences for managers of using single influence tactics and combinations of tactics. Academy of Management Journal, 35(3), 638-652. https://doi.org/10.2307/256490

Fuller Jr, J. B., Marler, L. E., \& Hester, K. (2012). Bridge building within the province of proactivity. Journal of Organizational Behavior, 33(8), 1053-1070. https://doi.org/10.1002/job.1780

Grant, A. M., \& Ashford, S. J. (2008). The dynamics of proactivity at work. Research in Organizational Behavior, 28, 3-34. http://doi.org/10.1016/j.riob.2008.04.002

Grant, A. M., Parker, S., \& Collins, C. (2009). Getting credit for proactive behavior: Supervisor reactions depend on what you value and how you feel. Personnel Psychology, 62(1), 3155. https://doi.org/10.1111/j.1744-6570.2008.01128.x

Hu, L. T., \& Bentler, P. M. (1999). Cutoff criteria for fit indexes in covariance structure analysis: Conventional criteria versus new alternatives. Structural Equation Modeling: A Multidisciplinary Journal, 6(1), 1-55. https://doi.org/10.1080/10705519909540118

Jowett, S. (2017). Coaching effectiveness: The coach-athlete relationship at its heart. Current Opinion in Psychology, 16, 154-158. https://doi.org/10.1016/j.copsyc.2017.05.006

Jowett, S., \& Shanmugam, V. (2016). Relational coaching in sport: Its psychological underpinnings and practical effectiveness. In Routledge international handbook of sport psychology (pp. 501-514). Routledge.

Kenny, D. A. (1996). The design and analysis of social interaction research. Annual Review of Psychology, 47, 59-86. https://doi.org/10.1146/annurev.psych.47.1.59

Knoll, M., Schyns, B., \& Petersen, L. E. (2017). How the influence of unethical leaders on followers is affected by their implicit followership theories. Journal of Leadership \& Organizational Studies, 24(4), 450-465. https://doi.org/10.1177/1548051817705296 
639 Kudisch, J. D., Fortunato, V. J., \& Smith, A. F. (2006). Contextual and individual difference factors predicting individuals' desire to provide upward feedback. Group \& Organization Management, 31(4), 503-529. https://doi.org/10.1177/1059601106286888

Latané, B. (1981). The psychology of social impact. American Psychologist, 36(4), 343. https://doi.org/10.1037/0003-066X.36.4.343

Marks, M. A., Mathieu, J. E., \& Zaccaro, S. J. (2001). A temporally based framework and taxonomy of team processes. Academy of Management Review, 26(3), 356-376. https://doi.org/10.2307/259182

Mason, R. J., Farrow, D., \& Hattie, J. A. (2020). Sports coaches' knowledge and beliefs about the provision, reception, and evaluation of verbal feedback. Frontiers in Psychology, 11, 2424. https://doi.org/10.3389/fpsyg.2020.571552

McCullagh, M. C., Sanon, M. A., \& Cohen, M. A. (2014). Strategies to enhance participant recruitment and retention in research involving a community-based population. Applied Nursing Research, 27(4), 249-253. https://doi.org/10.1016/j.apnr.2014.02.007

McNeish, D., An, J., \& Hancock, G. R. (2018). The thorny relation between measurement quality and fit index cutoffs in latent variable models. Journal of Personality Assessment, 100(1), 43-52. https://doi.org/10.1080/00223891.2017.1281286

Meindl, J. R., Ehrlich, S. B., \& Dukerich, J. M. (1985). The romance of leadership. Administrative Science Quarterly, 30(1), 78-102. https://doi.org/10.2307/2392813

Muthén, L. K., \& Muthén, B. (2017). Mplus user's guide: Statistical analysis with latent variables, user's guide. Muthén \& Muthén.

Nicholls, A. R., Earle, K., Earle, F., \& Madigan, D. J. (2017). Perceptions of the Coach-Athlete Relationship Predict the Attainment of Mastery Achievement Goals Six Months Later: A Two-Wave Longitudinal Study among FA Premier League Academy Soccer Players. Frontiers in psychology, 8, 684. https://doi.org/10.3389/fpsyg.2017.00684 
664 Oc, B., \& Bashshur, M. R. (2013). Followership, leadership and social influence. The Leadership Quarterly, 24(6), 919-934. https://doi.org/10.1016/j.leaqua.2013.10.006

Parker, S. K., Bindl, U. K., \& Strauss, K. (2010). Making things happen: A model of proactive motivation. Journal of Management, 36(4), 827-856.

Pierce, C. A., \& Aguinis, H. (1998). Using virtual reality technology in organizational behavior research. Journal of Organizational Behavior, 18(5), 407-410. https://doi.org/10.1002/(SICI)1099-1379(199709)

Rule, N., \& Ambady, N. (2010). First impressions of the face: Predicting success. Social and Personality Psychology Compass, 4(8), 506-516. https://doi.org/10.1111/j.17519004.2010.00282.x

Sapolsky R. M. (2005). The influence of social hierarchy on primate health. Science, 308 (5722), 648-652. https://doi.org/10.1126/science.1106477

Sauer, S. J. (2011). Taking the reins: The effects of new leader status and leadership style on team performance. Journal of Applied Psychology, 96(3), 574. https://doi.org/10.1037/aoo22741

Scandura, T. A., \& Williams, E. A. (2000). Research methodology in management: Current practices, trends, and implications for future research. Academy of Management Journal, 43(6), 1248-1264. https://doi.org/10.5465/1556348

Schafer, J. L. \& Olsen, M. K. (1998). Multiple imputation for multivariate missing-data problems: A data analyst's perspective. Multivariate Behavioral Research, 33, 545-571. https://doi.org/10.1207/s15327906mbr3304_5

Smither, J. W., London, M., \& Richmond, K. R. (2005). The relationship between leaders' personality and their reactions to and use of multisource feedback: A longitudinal study. Group \& Organization Management, 3O(2), 181-210. https://doi.org/10.1177/1059601103254912 
690 Sun, S., \& van Emmerik, H. I. (2015). Are proactive personalities always beneficial? Political 691 skill as a moderator. Journal of Applied Psychology, 10o(3), 966.

692 https://doi.org/10.1037/aoo37833

693 Sy, T. (2010). What do you think of followers? Examining the content, structure, and 694 consequences of implicit followership theories. Organizational Behavior and Human 695 Decision Processes, 113(2), 73-84. https://doi.org/10.1016/j.obhdp.2010.06.001

696 Uhl-Bien, M., Riggio, R. E., Lowe, K. B., \& Carsten, M. K. (2014). Followership theory: A review 697 and research agenda. The Leadership Quarterly, 25(1), 83-104.

$698 \quad$ https://doi.org/10.1016/j.leaqua.2013.11.007

699 Van Puyenbroeck, S., Stouten, J., \& Vande Broek, G. (2018). Coaching is teamwork! The role of need-supportive coaching and the motivational climate in stimulating proactivity in volleyball teams. Scandinavian Journal of Medicine \& Science in Sports, 28(1), 319-328.

702 van Vugt, M. V., Hogan, R., \& Kaiser, R. B. (2008). Leadership, followership, and evolution:

703 Some lessons from the past. American Psychologist, 63(3), 182-196.

704 https://doi.org/10.1037/ooo3-066X.63.3.182.

705 Whiting, S. W., Maynes, T. D., Podsakoff, N. P., \& Podsakoff, P. M. (2012). Effects of message, 706 source, and context on evaluations of employee voice behavior. Journal of Applied $707 \quad$ Psychology, 97(1), 182-182. https://doi.org/10.1037/aoo24871 
Table 1

Coaches' Competition Level Breakdown by Gender

\begin{tabular}{lccc}
\hline & & Demographic Category & \\
Competition Level & Males & Females & Combined \\
& $n(\%)$ & $n(\%)$ & $n(\%)$ \\
\hline Recreational & $13(7.9 \%)$ & $8(11.8 \%)$ & $40(17.2 \%)$ \\
Youth & $29(17.6 \%)$ & $11(16.2 \%)$ & $139(59.9 \%)$ \\
Collegiate & $100(60.1 \%)$ & $39(57.4 \%)$ & $32(13.8 \%)$ \\
Club & $23(13.9 \%)$ & $9(13.2)$ & \\
\hline
\end{tabular}

Note. Male coaches, $n=165$; Female coaches, $n=67$. 
Table 2

Coaches' Evaluations of Followership as a Function of Context

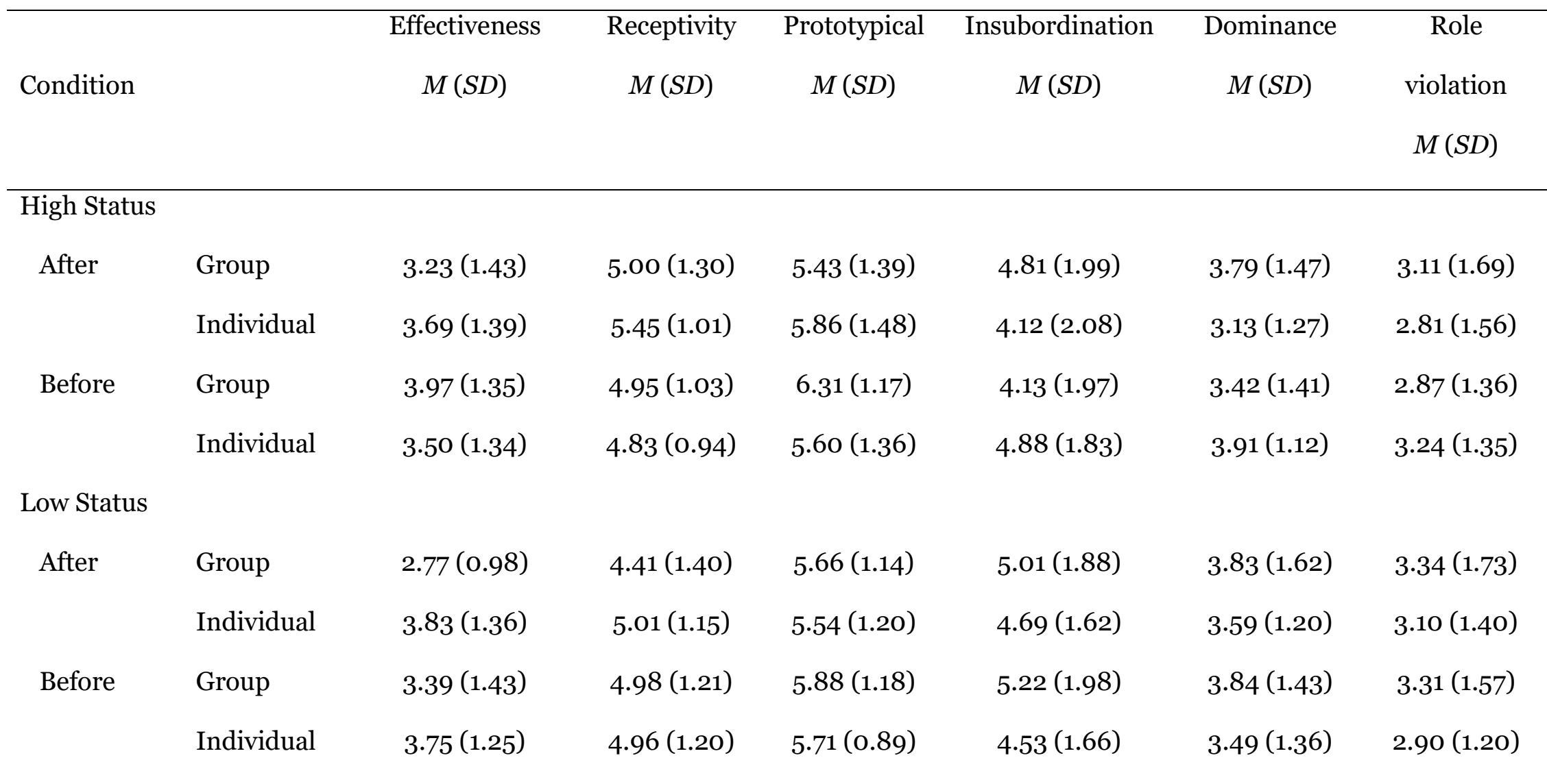

Note. Male coaches, $n=165$; Female coaches, $n=67$. High Status: the athlete engaging in the COF was described as a respected senior team member. Low Status: the athlete engaging in the COF was described as a newcomer to the team. After: the COF occurred after a decision was made. Before: the COF occurred before a decision was made. Group: The COF occurred in the presence of teammates. Individual: The COF occurred in a one-on-one setting with the coach. Scores on effectiveness and receptivity measures range from 1 (not at all) to 7 (very much so); prototypical and insubordination scores range from 1 (not at all characteristic) to 10 (extremely characteristic); dominance and role violation scores range from 1 (strongly disagree) to 7 (strongly agree). 